\title{
Comparison of Pregnancy Outcome in Non-Risk and High-Risk Antenatal Mothers
}

\author{
Chandra Metgud, M.D.
}

Associate Professor, Department of Community Medicine, J.N. Medical College, Belgaum, Karnataka, India

\section{A B S T R A C T}

Objectives:

1. To know the incidence of high risk pregnancy.

2. To study the pregnancy outcome in Non-risk and High-risk antenatal mothers.

Study Design: Longitudinal study.

Setting: Shindolli Village of Belgaum District.

Participants: All women in this village who were pregnant at the start of the study and who became pregnant during the study period.

Sample Size: 125 .

Statistical Analysis: Percentages and Chi-square Test.

Results: The incidence of High risk pregnancy was noted in 51(40.80\%) pregnant women. The various risk factors noted were: primigravida 18 years, grand multipara, pre-eclampsia, bad obstetric history, severe anaemia etc. Among 125 pregnancy outcome, 69(93.24\%) pregnant women in the non-risk group had good outcome compared to $34(66.67 \%)$ in the high risk group. The outcome of the pregnancy was significantly associated with presence of risk factors.

Conclusion: The high-risk pregnancies are due to early marriages and child bearing at an early age. In rural areas early marriages are perpetuated by tradition, belief and family needs to reduce expenditures. A high percentage of anaemia in the pregnant women was due to the fact that, majority of them belonged to low social classes which affect their dietary intake and purchasing power adversely. Another common factor noted in rural area was grand multiparity, due to the need for male child. JMS 2014; 17 (1): 16-19

Key Words: Pregnant women, Risk factors, Pregnancy outcome.

\section{INTRODUCTION}

Pregnancy and child birth is a physiological phenomenon, yet it predisposes the woman to several health hazards. The aim of preventive medicine is to ensure that throughout pregnancy and puerperium, every mother will have good health and every pregnancy may ultimately result in a healthy mother and healthy baby ${ }^{1}$. Certain proportions of pregnant women are at special risk of diseases, its complications or death because of their biological makeup, their environment or both. These factors are called "Risk Factors" which exert their effect either singly or in combination. Primigravida, high parity, too frequent pregnancies and that too at extremes of age, previous child

\section{Correspondence}

Dr. Chandra Metgud, M.D.

Associate Professor, Department of Community Medicine, J.N. Medical College, Belgaum, Karnataka, India Email: docchandra2006@yahoo.com loss are some of the universally recognized risk factors ${ }^{2}$. A high risk factor is defined as a factor that is significantly associated with the development of an adverse outcome, viz; different modes of delivery, preterm birth, still birth, and early neonatal death ${ }^{3}$. The present community based study was under taken to estimate the incidence of high risk pregnant women in a rural area of Belgaum and also to find out the pregnancy outcome.

\section{METHODS}

This longitudinal study was conducted in Shindolli village which is a rural field practice area of the Department of Community Medicine, J. N. Medical College, Belgaum. Shindolli, having population of 6335 comes under the Mutaga Primary Health Centre. The present study was conducted for a period of one year. All women (universal sample) in this village who were pregnant at the start of the 
study and who became pregnant during the study period were enrolled. A total of 125 pregnant women were enrolled in the study. Case identification was carried out with the help of anganwadi workers and the case load was crosschecked with female health worker record to identify any missed cases. During the initial visit, using a pre-designed and pre-tested questionnaire, information was collected by interviewing the pregnant women on socio-demographic variables. Each pregnant woman was then followed-up by fortnightly home visits till seven days after delivery. The details were noted down in a pre-designed and pre-tested follow-up proforma.

\section{RESULTS}

In the present study, out of 125 pregnant women, $67(53.60 \%)$ were between $20-24$ years, 30 (24.00\%) between 25-29 years, 23 (18.40\%) were between 15-19 years, $4(3.20 \%)$ between $30-34$ years and only $1(0.80 \%)$ was between 35-39 years. Out of the total pregnant women studied, majority $113(90.40 \%)$ were Hindus and only 12 $(9.60 \%)$ were Muslims. In our study, 66 (52.80\%) were housewives, $43(34.40 \%)$ were agricultural labourers, 11

Table 1: Distribution of High risk pregnant women according to risk factors

\begin{tabular}{|l|c|}
\hline \multicolumn{1}{|c|}{ Risk Factor } & Number \\
\hline Primigravida $\leq 18$ years & 11 \\
\hline Grand multipara & 8 \\
\hline Pre-eclampsia & 6 \\
\hline Bad obstetric history & 5 \\
\hline Severe anaemia & 4 \\
\hline Primigravida $\leq 18$ years + eclampsia & 2 \\
\hline Eclampisa & 2 \\
\hline Twins with hydramnios & 2 \\
\hline History of epilepsy & 2 \\
\hline History of previous LSCS and instrumental delivery & 2 \\
\hline Short statured primigravida $\leq 18$ years & 1 \\
\hline Grand multipara with history of asthma & 1 \\
\hline Pre-eclampsia with severe anaemia & 1 \\
\hline Rh-ve mother with severe anaemia & 1 \\
\hline Bad obstetric history with UV prolapse & 1 \\
\hline Short statured primigravida & $\mathbf{5 1}$ \\
\hline Rh -ve mother & 1 \\
\hline Total & 2 \\
\hline
\end{tabular}

$(8.80 \%)$ were weavers, $2(1.60 \%)$ each were service persons and coolies and only $1(0.80 \%)$ was tailor. Our study revealed that $81(64.80 \%)$ pregnant women were literates. Among them majority of the pregnant women, 36 (44.44\%) were educated upto primary level, 30 (37.04\%) upto high school and only $15(18.52 \%)$ women were educated after SSLC. It was also noted that $44(35.20 \%)$ women were illiterates. As regards to socio-economic status, $2(1.60 \%)$ belonged to class I, $6(4.80 \%)$ to class II, $28(22.40 \%)$ to class III, $51(40.80 \%)$ to class IV and $38(30.40 \%)$ belonged to class V according to Modified B.G. Prasad's classification.

The classification of pregnancies into high risk and non-risk was based on WHO criteria given in Park's text book. The incidence of high risk pregnancy was noted in $51(40.80 \%)$ pregnant women. Among 125 pregnant women, 74 $(59.20 \%)$ had no risk factors, $44(35.20 \%)$ had one risk factor and $7(5.60 \%)$ had 2 risk factors (Table 1). With regards to pregnancy outcome, $111(88.80 \%)$ had normal vaginal delivery and $14(11.20 \%)$ ended with caesarian section. On further analysis it was noted that $103(84.20 \%)$ pregnancy outcome were term singleton live birth (Table 2). Majority 69 (55.20\%) pregnant women delivered at hospital and remaining $56(44.80 \%)$ at homes. Among 125 deliveries, $69(55.20 \%)$ were conducted by doctors, 18 $(14.40 \%)$ by local practitioners at homes, $21(16.80 \%)$ by trained dais and health worker female and $17(13.60 \%)$ by untrained dais and family members.

The study showed that good pregnancy outcome was

Table 2: Distribution of pregnant women according to pregnancy outcome

\begin{tabular}{|l|c|c|}
\hline \multicolumn{1}{|c|}{ Pregnancy outcome } & Number & Percentage \\
\hline Term Singleton live birth & 103 & 84.20 \\
\hline Pre-term singleton live birth & 10 & 8.00 \\
\hline Pre-term twins live birth & 2 & 1.60 \\
\hline Still birth & 5 & 4.00 \\
\hline Early neonatal death & 5 & 4.00 \\
\hline Total & $\mathbf{1 2 5}$ & $\mathbf{1 0 0}$ \\
\hline
\end{tabular}


Table 3: Association between presence of risk factors and pregnancy outcome

\begin{tabular}{|l|c|c|c|c|c|c|}
\hline \multirow{2}{*}{ Risk Factor } & \multicolumn{2}{|c|}{ Good outcome } & \multicolumn{2}{c|}{ Bad Outcome } & \multicolumn{2}{c|}{ Total } \\
\cline { 2 - 7 } & Number & Percentage & Number & Percentage & Number & Percentage \\
\hline Absent & 69 & 93.24 & 5 & 6.76 & 74 & 100 \\
\hline Present & 34 & 66.67 & 17 & 33.33 & 51 & 100 \\
\hline$\chi^{2}=14.704$ & \multicolumn{7}{|c|}{$\mathrm{Df}=1$} & $\mathrm{p}=0.0001$ \\
\hline
\end{tabular}

observed in 69 (93.24\%) pregnant women belonging to non-risk group compared to $34(66.67 \%)$ in high-risk group (Table 3). Only term singleton live births weighing more than or equivalent to $2.5 \mathrm{~kg}$ were considered as good outcome based on WHO criteria given in Park's text book. So, as the risk factors appeared, percentage of pregnant women having good pregnancy outcome decreased $\left(X^{2}=14.704, p=0.0001\right)$.

\section{DISCUSSION}

The present study revealed that $59.20 \%$ had no risk factors and $40.80 \%$ had risk factors. Among $40.80 \%$ of pregnant women, $35.20 \%$ had one risk factor and $5.60 \%$ had 2 risk factors. In a prospective community based study conducted at Sirur, $81.5 \%$ pregnant women had no risk factors and $18.5 \%$ had risk factors. Among $18.5 \%$ of pregnant women, $15.1 \%$ had one risk factor, $2.6 \%$ had 2 risk factors and $0.8 \%$ had 3 or more risk factors ${ }^{4}$. The study showed that "at risk" pregnancy with age 18 years was $11.2 \%$. A study undertaken in a semi-urban community of Pune revealed that "at risk" pregnancy with maternal age 18 years was $25.00 \%{ }^{2}$

Our study revealed that $33.60 \%$ pregnant women were primigravida, $26.40 \% 2^{\text {nd }}$ gravida, $24.00 \% 3^{\text {rd }}$ gravida, $8.80 \% 4^{\text {th }}$ gravida and $7.20 \%$ of pregnant women were "at risk" with grandmultiparity. In a study conducted in villages around Hyderabad, 25.0\% women were primigravida, $26.4 \% 2^{\text {nd }}$ gravida, $22.3 \% 3^{\text {rd }}$ gravida, $11.8 \% 4^{\text {th }}$ gravida and $14.5 \%$ of pregnant women were "at risk" of grandmultiparity ${ }^{5}$. The study revealed that "at risk" primigravida with height $140 \mathrm{cms}$ were $4.76 \%$. In a study conducted in urban slum communities of Delhi, $11.0 \%$ of the pregnant women were "at risk" with height $140 \mathrm{cms}^{6}$. In the present study $69.60 \%$ of pregnant women were anaemic and among them $16.09 \%$ mildly anaemic, majority $77.01 \%$ were moderately anaemic and $6.90 \%$ of pregnant women were severely anaemic. In a study conducted in a rural area of Delhi, anaemia was noted in $96.5 \%$ of pregnant women and among them 50.9\% were moderately anaemic, $22.8 \%$ were mildly anaemic and $22.8 \%$ were severely anaemic ${ }^{7}$. In the general population $94-95 \%$ are $\mathrm{Rh}$ positive and 5-6\% are $\mathrm{Rh}$ negative ${ }^{7}$. Whereas, the present study revealed that $98.40 \%$ pregnant women were $\mathrm{Rh}$ positive and $1.60 \%$ pregnant women were "at risk" being Rh negative mothers. In our study $8.80 \%$ of pregnant women developed preeclampsia. Out of these majority 63.64\% women developed pre-eclampsia after 36 weeks of gestation. A study carried out in rural Karnataka, $0.4 \%$ of pregnant women had high blood pressure 9 . The hospital based study, conducted at Aligarh Muslim University, 4.03\% pregnant women had pre-eclampsia. Among them majority $68.21 \%$ developed between 33-36 weeks of gestation ${ }^{10}$.

\section{CONCLUSION}

To summarize, the incidence of high risk pregnancy in our study was $40.80 \%$. As compared to $93.24 \%$ in non- risk group, only $66.67 \%$ of pregnant women in the high risk group had good pregnancy outcome. So, it is very important in the rural setup to train the health worker females in identification of high risk pregnancies and timely referral to tertiary health care facilities.

\section{Acknowledgement}

We are extremely obliged to all the people of Shindolli, Anganwadi workers and Health workers for their kind cooperation throughout study period.

\section{REFERENCES}

1. Gupta SC, Nandan N, Goel N, Dabral SB, Maheshwari BB, Chandra M. Maternal factors and pregnancy outcome in hospital setting. Indian Journal of Community Medicine 1998; 23(1): 19-24

2. Dutta PK, Urmil AC, Gund SS, Dutta M. Utilization of Health services by high risk pregnant women in a semiurban community of Pune - An analytical study. 
Indian Journal of Maternal and Child Health 1990; 1(1): 15-19

3. Talsania NJ, Lala MK. Scoring of High risk pregnant women and related outcome. Indian Journal of Maternal and Child health 1991;2(3): 92-94

4. Pratinidhi A, Shrotri A, Shah U. Risk approach strategy in $\mathrm{MCH}$ care. Indian Journal of Community Medicine 1990; 15(2): $74-81$

5. Neela J, Ramalakshmi BA. Primary health care related awareness and practices of rural pregnant women. Indian Journal of Community Medicine 1992; 17(1): 21-25.

6. Kapil U, Pathak P, Tandon M, Singh C, Pradhan R, Dwivedi SN. Micronutrient deficiency disorders amongst pregnant women in three urban slum communities of Delhi. Indian Pediatrics 1999; 36: 983 89.
7. Gautam VP, Bansal Y, Taneja DK, Saha R. Prevalence of aneamia amongst pregnant women and its sociodemographic associates in a rural area of Delhi. Indian Journal of Community Medicine 2002; 27 (4): 157160.

8. Jain AK. Manual of practice physiology, 2nd Edn. New Delhi: A Vichal Publishing Company; 2001.

9. Matthews Z, Mahendra S, Kilaru A, Ganapathy S. Antenatal care, Care seeking and Morbidity in Rural Karnataka, India: Results of a prospective study. Asia Pacific Population Journal 2001; 16(2): 11-28

10. Amir A, Yunus M, Islam HM. Clinico-epidemiological study of factors associated with pregnancy induced hypertension. Indian Journal of Community Medicine 1998; 23(1): 25-29. 